\title{
ENTRE HISTÓRIA E MEMÓRIA: OLHARES DE EX- ALUNOS SOBRE O COTIDIANO ESCOLAR NO GRUPO ESCOLAR E GINÁSIO ESTADUAL - CÁCERES/MT
}

\author{
Alexandra Lima da Silva ${ }^{1}$ \\ lattes.cnpq.br/3035434886894830 \\ Giuslane Francisca da Silva ${ }^{2}$ \\ lattes.cnpq.br/3394251044954546
}

\begin{abstract}
Resumo: As escolas também guardam memórias, sendo, portanto, espaços nos quais se tecem parte da memória social de uma determinada cidade. O conhecimento do universo escolar possibilita compreender as instituições escolares para além de sua finalidade específica (a de ensinar), mas percebê-las como territórios de lenta aprendizagem do mundo exterior. Considerando que as memórias se apresentam como ricas fontes documentais, nas quais expressam sentidos e acontecimentos que não estão registrados nos documentos escritos, dessa maneira, os relatos orais foram tomados aqui como fontes para se pensar o cotidiano escolar do Grupo Escolar Esperidião Marques e Ginásio Onze de Março, na cidade de Cáceres/MT, na primeira metade do século XX, levando em consideração todas as peculiaridades envoltas no processo de rememoração. O movimento se deu na busca de pensar o cotidiano e o processo escolar a partir dos olhares de ex-alunos, apontando a relevância da memória como fonte para pesquisa em história da educação.
\end{abstract}

Palavras-chave: Memória; História da Educação; Cotidiano Escolar.

\section{BETWEEN HISTORY AND MEMORY: A FORMER STUDENTS VIEW ABOUT THE SCHOOL ROUTINE IN THE SCHOOL GROUP AND STATE MIDDLE SCHOOL - CÁCERES/MT}

\begin{abstract}
The schools also hold memories, becoming a place where the social memories of a particular city are weaved. The knowledge of the school universe allows understanding the educational institution beyond it specifics purpose (to teach) perceiving them as territories slowly learning the outside world. Whereas the memories present themselves as rich documentary sources that express meaning an events that are not recorded in written documents. In this way, the oral accounts are taken as a source to thinking the school routine in the School Group Esperidião Marques and

\footnotetext{
${ }^{1}$ Doutora em Educação. Docente da Universidade do Estado do Rio de Janeiro (Brasil). Contato: alexandralima1075@gmail.com.

2 Mestre em História pela Universidade Federal do Mato Grosso (Brasil). Contato: giuslanesilva@hotmail.com.
} 
Middle School Onze de Março of Cáceres/MT in the second half of the twentieth century, taking into account all the peculiarities wrapped in the remembrance process. The movement occurred in the search of thinking the day-routine and the school process from the former students, pointing the relevance of the memory as a research source in history of education.

Keywords: Memory; History of Education; School Routine.

\section{Considerações iniciais: contribuições da memória para a história da educação}

Walter Benjamin em O narrador (1994, p. 197) assinala que a "arte de narrar está em via de extinção", são poucas pessoas que sabem narrar devidamente, isto se explica pela dificuldade em "intercambiar" as experiências. Com o passar dos tempos, a arte de narrar vai sendo sucumbida pelas novas atrações, entretenimentos, consequentemente saberes, acontecimentos/eventos, experiências, vivências, sociabilidades, amizades, entre outras facetas que envolvem o cotidiano escolar vão sendo esquecidos pelos indivíduos. Por sua vez, as narrativas orais nos proporcionam conhecer um passado que, na maioria das vezes, subsiste apenas na memória daqueles que o viveram. Reconhecendo as ricas contribuições dos relatos orais para se "conhecer" o passado, buscamos nesse presente texto discutir o cotidiano escolar no Grupo Escolar Esperidião Marques e Ginásio Onze de Março a partir das narrativas orais de ex-alunos dessas instituições. Para tanto, serão utilizados relatos de quatro ex-alunos, são esses os senhores Lúcio Morais, Paulo Moreira, Gregório Costa e dona Clarice Arruda3. O movimento se deu na busca de pensar o cotidiano e o processo escolar a partir dos olhares de ex-alunos, apontando a relevância da memória como fonte para pesquisa em história da educação.

As instituições educativas, assim como seus sujeitos, são possuidoras de uma memória assentada nas tradições orais que são transmiti-

\footnotetext{
3 Embora possua carta de cessão autorizando a citação total e/ou parcial das entrevistas optei por utilizar pseudônimos, mantendo preservadas as identidades dos entrevistados.
} 
das pelas gerações que se sucedem e contemplam uma cultura escolar marcada por práticas cotidianas vividas no espaço escolar. As escolas também guardam memórias, sendo, portanto, espaços nos quais se tecem parte da memória social de uma determinada cidade. Desse modo, o conhecimento do universo escolar possibilita compreender as instituições escolares para além de sua finalidade específica (a de ensinar), mas percebê-las como territórios de lenta aprendizagem do mundo exterior, isto é, uma educação para além da sala de aula, educação para a vida. Os códigos desse universo transparecem na definição de um espaço que lhe é próprio no uso do tempo, nas regras disciplinares, nas vestimentas específicas e numa pluralidade de objetos (NUNES, 2003).

Em seus relatos orais, os ex-alunos rememoraram vários aspectos que não envolvem apenas o que ocorre no interior das escolas, mas também o ir e vir, as normas, os professores, entre outros aspectos. Mediante suas narrativas, reconstruíram e ressignificaram um passado distante, possibilitando conhecer e compreender o espaço escolar e suas significações para aqueles que os compõem, especialmente os alunos que, no interior desse contexto, constituem o elemento fundamental para as dinâmicas que se estabelecem nas escolas.

As descrições sobre a escola e o cotidiano escolar permitiram compreender um pouco mais sobre a educação em Cáceres na primeira metade do século XX, especialmente sobre o Grupo Escolar e o Ginásio Estadual. Também revelaram circunstâncias que não ficaram registradas nos documentos oficiais, como as travessuras, as redes de amizades, as sociabilidades infantis, os castigos, as normas, enfim, um conjunto de elementos que possibilitam "desenhar" e consequentemente conhecer mais sobre a educação na cidade. Para tanto, relembrar o espaço escolar é, sobretudo, trazer ao tempo presente a memória enraizada nos gestos de um local concreto. Ela se torna emblemática quando é conferida à instituição, na qual se viveu, grande parte de sua infância e adolescência. Constitui-se ainda na possibilidade de remeter-se "a um tempo preciso que a lembrança nostálgica muitas vezes esgarça. É o sinal de que se reconhece e pertence a certo grupo social e a determinada geração (...) a 
escola como lugar de memória é simultaneamente material, simbólica e funcional" (NUNES, 2003, p. 9).

As memórias são complexos processos de subjetivação marcados pelos espaços de convivência dos indivíduos, isto é, os indivíduos rememoram aquilo que faz parte da memória do grupo a qual são partícipes (HALBWACHS, 2003). As memórias ancoram-se em espaços e lugares nos quais os sujeitos circulam, nos mais distintos grupos sociais, são produtoras de significados que contribuem para a fusão do sentido e/ou intenção da rememoração com a intencionalidade das palavras. Para além de fenômeno individual e psicológico, como antes a memória era percebida, ela é considerada atualmente como um fenômeno social, uma construção que provém das relações sociais estabelecidas pelos atores sociais, transcendendo a esfera individual, como já assinalado.

Desse modo, entende-se a memória como o contexto em que a identidade é praticada. A linguagem, por sua vez, conforme assinala Custódio (2014), constitui-se em elemento principal da memória coletiva, pois é ela que possibilita o contato entre o passado e o presente, estabelecendo laços de solidariedade, sentimentos além das mais diversas experiências, costumes e tradições de um grupo social. O ato de narrar envolve um processo contínuo de reconstrução e transformação do que é narrado. As diferentes perspectivas sobre um mesmo ocorrido/evento podem ser pensadas a partir do princípio de que a narrativa se dá mediante a escolha do que narrar, como e para quem narrar.

As instituições educativas guardam elementos utilizados na infância e na juventude como um todo, tais como normas, transmissão de valores, uniformes, caminho percorrido até à escola, brincadeiras e desafios, experiências com o grupo, material didático utilizado e outros acontecimentos que ganham sentido na relação social com o cotidiano (TEIXEIRA, 2015, p. 03). Tais elementos mostram que a escola, como lugar de memória, é ao mesmo tempo simbólica e material. Para tanto, é necessário se atentar para as percepções que alunos e alunas possuem dessas instituições, bem como do processo de escolarização como um todo. É esse movimento que proponho realizar. 
Ao narrar sobre a escola e as representações sociais acerca desta, o ex-aluno se encontra inserido numa história em curso, viva e em permanente construção, cujos reflexos dessa construção são facilmente percebidos no cotidiano desses sujeitos. Essa especificidade da história demonstra a contribuição da memória para o conhecimento de um determinado evento/fato, nesse caso, da história da educação, uma vez que tal perspectiva, "un presente es el contenido completo de una memoria viva (...), aunque el tiempo este en ella ordenado según la secuencia pasadopresente" (ARÓSTEGUI, 2004, p. 162). A memória individual reúne em si significados da memória social de um determinado grupo social, herdada num processo "dialético, capaz de construir parâmetros sociais e, por sua vez, ajudando a compreender as representações sociais construídas pelos sujeitos analisados" (CARMO, 2011, p. 36). Feitas essas considerações, nos parágrafos que se seguem, analisamos/trabalhamos as memórias de ex-alunos sobre o cotidiano escolar nas duas instituições em questão, o Grupo Escolar e posteriormente o Ginásio Onze de Março.

\section{Narrativas sobre o cotidiano escolar: Grupo Escolar Esperidião Marques}

A consolidação dos Grupos Escolares, constituídos como imponentes instituições de ensino, está ligada diretamente ao processo de desenvolvimento municipal e regional do Estado de Mato Grosso. Surgiu acompanhando o molde educacional desenvolvido por volta de 1890 e 1896, no estado de São Paulo. Seguindo o modelo de modernização do ensino em curso em várias localidades do país, o governo da província autorizou a criação dos Grupos em 1908 mediante a resolução n ${ }^{\circ} 508$ de 16 de outubro, contudo, só foi concretizada em 1910 com a vinda de Mello e Kuhlmann com o intuito de reorganizarem o ensino mato-grossense (SÁ, 2007).

A institucionalização da escola primária, centrada nos ideais republicanos, foi inicialmente gestada em São Paulo, que exportou o modelo para outros Estados, entre eles Mato Grosso, cujo projeto de moderni- 
zação foi incorporado pelas elites políticas regionais. Esse modelo de escola se estendeu a todas as regiões do país como parte do projeto de modernização do Estado Republicano Brasileiro, que idealizava a reforma social e a difusão da cultura popular, tal ideário necessitava alcançar todas as regiões do país, por mãos longínquas que fossem, pois entendiam que os rumos da "nação dependiam da qualidade de suas instituições, observando-se as interseções da dimensão política, social, econômica, jurídica, moral e psíquica da coesão social” (SILVA, 2011, p. 99). O objetivo consistia, sobretudo, em promover a transformação da sociedade brasileira a partir da escola primária.

Os Grupos Escolares se notabilizavam pelo ensino misto, bem como métodos de ensino considerados mais modernos, como o ensino simultâneo e a organização homogênea dos alunos, sendo distribuídos em classes e séries, estabelecendo uma relação entre série e idade do aluno.

O Grupo Escolar Esperidião Marques surgiu no cenário do município de Cáceres em 4 de fevereiro de 1912, passando a ser uma importante instituição escolar de Mato Grosso, alcançado pelo projeto republicano de ensino. O professor Venâncio José da Silva foi um de seus fundadores, sendo designado para diretor o normalista paulista José Rizzo (SILVA, 2011). Seu funcionamento passou a ocorrer num prédio localizado na Rua General Osório, onde hoje funciona o Arquivo Municipal. Neste local, "se agruparam três escolas: a) a masculina que tinha como diretor Professor Octavio Motta; b) a feminina com a professora Ritta Garcia e c) a mista com a professora Escolástica Botelho" (SILVA, 2011, p. 108).

Em 1913, o Coronel José Dulce doou ao governo do estado um terreno para a construção de um edifício próprio, onde mais tarde iria funcionar o Grupo Escolar. A construção do edifício próprio do Grupo Escolar Esperidião Marques teve início no ano de 1913 sendo concluída em 1920 na esquina da Praça Duque de Caxias, área central da cidade. O prédio foi inaugurado em o9 de março do referido ano, no entanto, somente em junho de 1924 passou a designar-se Grupo Escolar Esperidião Marques em homenagem ao presidente do Estado, Manuel Esperidião da Costa Marques (SILVA, 2011). O Grupo Escolar de Cáceres/MT, bem como os demais instalados em várias partes do território nacional, era uma 
instituição de ensino primário que se destacava, já assinalado, como símbolo da dita modernidade, tão propalada pela Primeira República.

Assim que fora fundado, o Grupo Escolar rapidamente se tornou uma das principais instituições de ensino de Cáceres, oferecendo uma educação calcada nos valores morais e ideais republicanos. Sobre a vida escolar na presente instituição, os depoentes falaram das mais variadas questões: tempo em que estudaram, professores(as), diretores, colegas, normatizações, entre outras questões. Como se pode ver nos relatos do sr. Lúcio Morais, de 94 anos, de família classe média alta, que viveu toda sua vida adulta na cidade, tendo se dedicado ao ofício de cirurgião dentista, declara que em 1928 iniciou o ensino primário no Colégio Imaculada Conceição, posteriormente ingressou no Colégio São Luiz, também denominado pelos entrevistados de Colégio dos Padres, permanecendo neste durante dois anos. Em 1934 foi matriculado por sua mãe no Grupo Escolar, iniciando então o quarto ano do primário. Narrando sobre o processo de transição entre um colégio e outro, nas palavras do entrevistado: "eu estudei no Colégio das Irmãs, em vinte e oito. Vinte e oito; aí, do Colégio das Irmãs, eu passei dois anos no Colégio dos Padres (...) eu passei dois anos lá no Colégio dos Padres, e minha mãe me tirou e fui pro colégio do Grupo, em trinta e quatro, no quarto ano. Fiz o colégio do Grupo no quarto ano (...)" (MORAIS, 2005). O entrevistado concluiu no Grupo Escolar o ensino primário, em seguida foi para a capital Cuiabá para se dedicar aos cursos preparatórios para prestar o Admissão4, tendo sido aprovado, ingressou no ensino secundário no Liceu Cuiabano. O entrevistado narra sobre esses eventos que marcaram, segundo ele, positivamente sua vida:

\footnotetext{
4 Como projeto de reformulação do ensino secundário, em 1931 ocorreu a chamada Reforma Francisco Campos (Decretos n. ${ }^{\circ}$ 19.890, de 18 de abril de 1931, e n. ${ }^{\circ}$ 21241, de 4 de abril de 1932), na qual instituía o Exame de Admissão ao Ginásio, isto é, o aluno que pretendesse cursar o secundário deveria ser aprovado em um rigoroso exame. $\mathrm{O}$ decreto também estabeleceu um caráter nacional a esse exame. $\mathrm{O}$ exame admissional perdurou de 1931 a 1971 sendo extinto pela Lei 5.692/71, sua permanência durante todo esse período foi justificada pela falta de escolas para todos, ao mesmo tempo em que poucos conseguiam ser aprovados no exame e ingressar no ensino secundário.
} 
Eu estudei em trinta e cinco, de janeiro até agosto, com ela (professora Normélia) justamente tava me preparando pra ir pra Cuiabá fazer o Admissão; eu daqui saí em novembro, fui pra Cuiabá, onde eu estudei (...); eu tenho um livro de Cuiabá que esses professores meus tão no livro. Eu estudei num colégio do Isaac Povoas, me preparando pra fazer o Admissão, pra entrar no ginásio, porque tinha que fazer o exame pra poder entrar pro ginásio, tá entendendo? E aí, tanto é que nós fizemos o Admissão e aqueles que tiveram nota mais alta foram aproveitados para o Liceu e os que tiveram nota mais baixa foram para o colégio Salesiano, dos padres, porque tinha sido aberto nesse ano. Então todos foram pra lá; aliás, a farda deles era uma beleza, por que melhor do que o Liceu era a farda deles. Mas, o Liceu era um dos ginásios mais falado do Brasil! Era conhecido o Liceu Cuiabano (...) (MORAIS, 2005).

No trecho da entrevista acima, o sr. Lúcio orgulhosamente fala do seu processo de ingresso no ensino secundário, pontuando que ficou entre os primeiros colocados no Admissão, por isso, ingressou no Liceu Cuiabano, que nesse período era uma referência no que diz respeito ao ensino secundário, de acordo com as palavras do entrevistado que não hesita em afirmar o privilégio que tivera em estudar numa instituição tão renomada como o Liceu, o que de certa maneira não passa de exageros, num claro objetivo de demonstrar "superioridade" frente os demais, não escondendo o "orgulho" de ter cursado o secundário na instituição em questão. O entrevistado faz questão de nomear as personalidades políticas que conhecera durante esse período, como Isaac Póvoas e Filogônio Correa.

Continuando sua narrativa sobre os tempos em que passara no Liceu Cuiabano, o sr. Lúcio descreve então sobre alguns professores que tivera no decorrer do secundário:

Era conhecido o Liceu Cuiabano, com excelentes professores, tanto é que nesse livro, ainda vi lá, Filogônio Correia, foi deputado, né? Joerci Jacó, Zaramella, era um italiano, de geografia, tinha seu Metelo, era de geografia também, tinha professor de matemática, excelente professor, Humberto de Campos; Era um colégio famoso! Um ginásio de (...) mas era puxado mesmo! Eram cinco anos (MORAIS, 2005). 
Como já foi assinalado em outro momento desse trabalho, assim que concluiu o secundário, o sr. Lúcio foi para o Rio de Janeiro onde passou a residir com uma tia. Posteriormente mudou-se para Niterói a convite de um tio, tendo nessa cidade cursado faculdade de medicina, mais dois anos complementar na área de Odontologia, sua área de atuação.

Outra entrevistada, a comerciante dona Clarice Arruda, de 61 anos, nasceu em Cáceres e viveu toda sua infância na Rua Quinze, como faz questão de frisar, frequentou inicialmente o Colégio Imaculada Conceição, cursando neste o primeiro e o segundo ano ( $1^{\mathrm{a}}$ e $2^{\mathrm{a}}$ séries), no terceiro ano ingressou no Grupo Escolar, concluindo nessa última instituição o ensino primário. Hoje rememorando sobre o tempo que estudara no colégio, a entrevistada nomeia alguns professores, bem como colegas de classe que marcaram sua vida escolar:

no terceiro ano mudei pro Ginásio Estadual, chamava de Grupo Escolar Esperidião Marques, a minha professora nesse colégio foi Terezinha Cuiabano no terceiro quarto ano já foi Zuma Lucatelli e lá encontrei outros tipos de colegas; o Estadual já é diferente, já é mais assim extrovertido, as crianças são diferentes. Esse foi o estudo lá. Aí fizemos a Admissão com três meses; meu colega de infância, uma maravilha que eu tenho adoração até hoje, o Ninomya Miguel, Balbina Lobo, Darci de Oliveira, Tetê Faria, eu sei que era aquela turma maravilhosa, que tinha aquela união no Colégio, era uma família! (ARRUDA, 2006).

Os relatos de dona Clarice trazem, além da compreensão das teias de relações estabelecidas no contexto escolar, importantes informações sobre as normas que regiam o Grupo Escolar. De maneira entusiasta a entrevistada faz referência ao conjunto de normatizações que regiam a instituição, para ela, o tempo levou consigo o "respeito" que os alunos possuíam por aqueles que compunham a unidade escolar. E citando os tempos em que estudara, acentua a existência do "respeito" dos alunos para com os funcionários do colégio: "a gente respeitava desde seu Antônio que limpava o quintal como os professores; os professores tinham autoridade dentro de uma classe, a gente não fazia bagunça porque era chamada atenção a gente se sentia envergonhado, assim é que era" (ARRUDA, 2006). A terminologia "respeito", que a entrevistada faz refe- 
rência, pauta-se mais nos princípios de autoritarismo empregado pelos(as) professores(as) da instituição.

Dona Clarice em tom um tanto saudosista recorda sobre a amizade existente entre o corpo discente do colégio, especialmente entre os(as) colegas de classe. Com certo entusiasmo relata sobre as normatizações do Grupo Escolar, como se pode ver no trecho a seguir:

a amizade de classe dos alunos era demais um com o outro; a gente se tornava completamente correto nas obrigações do colégio; na hora da merenda, nove horas era a merenda, todo mundo sentadinho, tomando o seu lanche, quando terminava ficava na fila a professora falava vamos cantar o hino nacional ou então o hino à bandeira, outro dia era o hino do marinheiro, antes de ir pra classe; tinha essas baguncinhas, mas chegava a professora falava com os alunos murchava todinhos e sentava quietos para a explicação do quadro (ARRUDA, 2006).

De acordo com as informações levantadas, o Grupo Escolar passou a aplicar o exame de Admissão para ingresso no ensino secundário, como é possível notar nos relatos do sr. Paulo Moreira que, embora tenha cursado o ensino primário no Colégio Imaculada Conceição, em alguns trechos de sua entrevista, faz referência ao exame de Admissão prestado no Grupo Escolar. Segundo ele, o exame se dava da seguinte maneira: em um dia era aplicado o exame de português, que era disciplina eliminatória, no dia seguinte todos(as) que haviam prestado o exame se reuniam na porta do Grupo, à medida que os nomes dos aprovados nesta fase eram lidos, eles iam subindo as escadas para realizar a prova de matemática, aquele(as) que não tinham seus nomes lidos estavam reprovados e deveriam esperar mais um ano para novamente realizar a seleção.

Com o exame de matemática repetia-se o mesmo sistema, caso os(as) candidatos(as) fossem aprovados(as) eram submetidos(as) aos exames de história e geografia, que não consistiam em disciplinas eliminatórias. Os professores responsáveis pela aplicação dos exames foram os professores Natalino Mendes, para português; Gico Curvo, para matemática; Benete Jorge da Cunha, para história; e Poty Coelho, para Geografia, segundo o sr. Paulo, a média para aprovação era quatro. A seguir, repro- 
duzo um trecho da entrevista em que descreve sobre o processo de seleção para ingresso no ensino secundário, o Admissão:

Lá (no Grupo Escolar) que eu fiz o Curso de Admissão ao Ginásio, o professor que fazia o exame final do curso de português era o Natalino e matemática era Gico Curvo, português e matemática eram matérias eliminatórias, era feita a prova de português, vamos supor hoje de manhã, aí no dia seguinte cedo, nos reuníamos na entrada do Grupo Escolar, onde tem aquelas escadas e era lido o resultado da prova de português, à medida que ia lendo o nome dos aprovados, eles iam subindo as escadas para fazer a prova de matemática, e os que não tinham passado em português, iam para casa chateados, pois estavam eliminados, e os outros entravam e faziam a prova de matemática que também era eliminatória, depois de fazer a matemática, também era o mesmo processo no dia seguinte, Geografia e História que não eram eliminatórias; o professor de geografia era Poty Coelho, que era professor do ginásio, a gente enfrentar um professor do ginásio era uma tremedeira mesmo, a professora de história era Benete Jorge da Cunha, você tinha que alcançar a média que era quatro, olha que tirar quatro antigamente não era fácil (MOREIRA, 2006).

De acordo com o trecho da entrevista, no primeiro ano do ensino primário, o sr. Paulo sofreu processo de reprovação, segundo ele, o principal motivo foi sua falta de dedicação aos estudos, visto que assim que chegava do colégio, ao invés de fazer as atividades para casa, ia juntamente com seus amigos tomar banho no rio Paraguai e de lá regressavam apenas na entrada da noite. Outras vezes, com a pequena canoa da família permaneciam por longo período remando no Paraguai, ou ainda, em posse da "espingardinha flaubel" da família, "ia caçar com os colegas, e estudo nada” (MOREIRA, 2006). Atitudes, segundo ele não consentidas por sua mãe que não hesitava em aplicar castigos e "surras":

Eu me safava em português, com o professor Natalino, me safava sim pela redação, pois a gramática nunca foi o meu forte (risos), mas acho que pouca gente sabe a gramática do português puro; então eu entrei no ginásio; na primeira série não fui bem, reprovei na primeira; aí minha mãe era dureza, como deveriam ser até hoje, benditas surras que minha mãe me deu, depois, se não fosse por isso, pôxa, não fiquei com trauma, até agradeço por ela ter me surrado bastante, que eu chegava da aula, em vez de estudar, pulava neste rio Paraguai, só voltava à noite pra ca- 
sa, já voltava sabia que ia apanhar, jantar e dormir. (risos) (MOREIRA, 2006).

O sr. Paulo não apresentava bons resultados nos estudos, visto que não se dedicava o suficiente para "tirar boas notas", como ele mesmo afirma, sendo assim, entrou em um acordo com sua mãe, que o enviou para o internato do Colégio Dom Bosco, digo acordo, pois sua mãe pretendia enviá-lo a uma escola militar, no entanto, após muitas negociações, ela aceitou mandá-lo para o internato em Campo Grande, solução encontrada a fim de fazê-lo se dedicar aos estudos. Nessa instituição, o sr. Paulo concluiu o ginasial (secundário) e em seguida, no ano de 1962, ingressou no curso de contabilidade no Colégio Oswaldo Cruz, também em Campo Grande. Retornando em 1964 para Cáceres/MT com o objetivo de assumir os negócios da família, tendo em vista que seu pai estava com a saúde debilitada, vindo a falecer um ano depois, em 1965. O entrevistado prosseguiu com os negócios da família e, em 1978, ingressou na primeira turma do curso de Letras do IESC (hoje Universidade do Estado de Mato Grosso), tendo concluído o curso quatro anos depois.

\section{Ginásio Onze de Março}

Nas narrativas utilizadas para a construção desse trabalho, apenas um entrevistado afirma ter estudado nessa instituição, o sr. Gregório Costa. No entanto, seus relatos oferecem muitos elementos para se conhecer um pouco sobre o Ginásio Onze de Março, posteriormente denominado de Escola Estadual Onze de Março, primeira instituição de ensino secundário de Cáceres/MT, que foi criada com base na Lei n. ${ }^{\circ}$ 27, de 22 de outubro de 1947, fruto de lutas que se arrastaram por longos anos, no entanto, as aulas só tiveram início em abril do ano de 1948.

Em Cáceres/MT até meados da década de 1940, quando a cidade ainda não contava com ensino secundário, os filhos das famílias que possuíam recursos financeiros assim que concluíam o primário, em geral no Colégio São Luiz ou Imaculada Conceição e posteriormente no Grupo Escolar, iam cursar o ginasial (ensino secundário) em Cuiabá, Corumbá ou 
Campo Grande. Dessa minoria, um seleto grupo tinha a oportunidade de ingressar no ensino superior, em geral no Rio de Janeiro, São Paulo, ou em cidades mineiras como Viçosa e Ouro Preto, como já foram apontados alguns casos em parágrafos acima. Estes, por sua vez, regressavam "doutores", como médicos, cirurgiões dentistas, advogados, contadores, engenheiros entre outras profissões rentáveis, em geral, eram os mesmos que mais tarde fariam parte dos poderes administrativos da cidade; enfim, o poder tanto político quanto econômico permanecia nas mãos de uma pequena parcela da população.

No caso das meninas a realidade em geral era bem pior, pois, de acordo com o pensamento reinante da época, as mulheres necessitavam apenas saber ler, escrever e dominar as quatro operações da matemática. Posterior a isto, cabia-lhes bordar, costurar, cozinhar e eventualmente tocar piano, à espera de um "bom partido". Essa mentalidade machista que imperava na sociedade, acarretava que a maioria dos pais dificilmente se importavam com a educação das filhas, quando muito as permitiam concluir o ensino primário disponível na cidade, nas narrativas aqui trabalhadas há casos que exemplificam essa realidade. Outro fator que agravava essa situação era o fato de Cáceres até 1948 não possuir ensino ginasial.

Em 1948, mais precisamente no dia primeiro do mês de abril, iniciaram as aulas no Ginásio Estadual Onze de Março, que posteriormente viria a se chamar Escola Estadual Onze de Março, também conhecido como CEOM. A fundação desse colégio se deu mediante ação do capitão do Exército Cândido Nunes da Silva, que deu início a um projeto de criação de um colégio e para tal fim convidou para ajudá-lo o cacerense Natalino Ferreira Mendes, recém-chegado de Cuiabá, onde cursara o secundário, este fora também professor de português durante muitos anos, além de exercer o cargo de diretor. O colégio, assim que fora fundado, funcionava em uma casa da família de Cândido Nunes; inicialmente contava com quatro turmas de primário e uma de admissão ao ginásio.

O colégio atendia tanto o público feminino quanto o masculino, incialmente, segundo relatos de ex-professores, os pais hesitavam em matricular suas filhas no colégio, pois viam como inadmissível meninas 
com idade acima de 10 anos frequentarem uma escola na qual meninos estudariam na mesma classe que suas filhas. Foi necessário que os professores fossem às casas dos pais das crianças, especialmente das meninas, na busca de convencê-los a matricularem suas filhas no colégio, a ação foi exitosa. No ano de fundação, os professores e demais equipe escolar conseguiram reunir um grupo de 60 estudantes para se submeterem ao exame de Admissão, iniciando em abril a primeira turma do curso ginasial de Cáceres. Nos primeiros anos do colégio, compunham o corpo discente apenas filhos das camadas mais abastadas da cidade (BAPTISTA, 1998). A fundação do Ginásio Onze de Março possibilitou que a parcela populacional desprovida de recursos financeiros tivesse a oportunidade de cursar o secundário, bem como tornou o ensino primário gratuito acessível, obviamente que isso não se deu repentinamente.

O sr. Gregório Costa, único dos entrevistados que frequentou o Ginásio, nasceu na fazenda da família, na região do Sepotuba, nas proximidades de Cáceres. As primeiras letras lhe foram ensinadas por uma tia que lecionava para as crianças na fazenda, posteriormente mudou-se para Cáceres e passou a frequentar o Ginásio Estadual. Cursou os quatro anos do primário e em seguida prestou o Admissão, juntamente com um de seus dez irmãos. Como foi aprovado, ingressou no ensino secundário do Ginásio Estadual. Assim que concluíra o secundário, como seu pai encontrava-se muito doente, foi necessário abandonar os estudos para se dedicar à fazenda e a seus dez irmãos menores, permanecendo na fazenda até 1954 quando se mudou novamente para Cáceres para ingressar no Exército. Ele serviu às forças armadas por dez meses, durante esse intervalo fez o curso para cabo, depois para sargento, ao final desse tempo, retornou para a fazenda e ali continuou até se casar:

Muito bem, então, comecei aqui no colégio Onze de Março, primeiro ano primário, fiz os quatro anos lá e na época tinha o Admissão pra ir pro ginásio, fiz em três meses pra começar o ginásio da época, passamos, eu e meu irmão Valter; fizemos o ginásio já com Natalino Ferreira Mendes que foi nosso primeiro diretor do Onze de Março e a minha primeira professora foi a Ercília Rondon, esposa do Luiz Jorge. Fiz o ginásio lá e quando terminou, coincidiu com a doença de meu pai, então eu tive que largar de estudar e ir pra fazenda que tinha mais dez irmãos pa- 
ra ajudar criar; fui para lá e fiquei até na época de servir; em 1954, vim servir o Exército aqui, fiquei dez meses; fiz curso de cabo, de sargento (...). Deixando o Exército, voltei para fazenda lá com meu pai, ele já tava doente e fiquei até para casar (COS$\mathrm{TA}, 2005)$.

O sr. Gregório salienta que o Ginásio funcionava na rua Coronel Dulce5. Os relatos do entrevistado permite conhecer as dinâmicas e amizades estabelecidas entre os(as) alunos(as), como, por exemplo, as partidas de futebol com laranja seca e calçados durante no intervalo, o que demonstra a existência de sociabilidades dentro das escolas, assim como traz ao conhecimento uma série de normas que regiam a instituição. Normas estas muito parecidas com as do Colégio Imaculada Conceição e São Luiz, já discutidas em outro momento dessa pesquisa, como as filas para entrada e término das aulas e normas que valiam também para saída e volta dos intervalos:

No nosso recreio na época, nós fazíamos futebol no pátio do colégio; o Onze de Março funcionava ali na rua Coronel Dulce, em frente àquela floricultura, ali que era o Colégio e o pátio do recreio era pequeno, e nós fazíamos o futebol com laranja seca e calçado, então era só na base da botina; quando voltava pra sala de aula era o nego sujo, riscado de botina (...) Pra sair pro recreio, saía em fila; hora que tocava a campainha para recolher para a aula, entrava na fila e voltava em fila e no começo da aula tocava o hino nacional, para poder ir pra sala de aula; isso era todos os dias; na hora de sair também era fila para lá e para cá (COSTA, 2005).

Em seus relatos o sr. Gregório nomeia vários professores que tivera no Ginásio - alguns adorados por ele, outros não -, assim como as disciplinas, por exemplo, o inglês ministrado pela professora Clara que, segundo ele, sempre favorecia os alunos mais velhos, por essa razão não gostava da disciplina; o professor de geografia, Poti Coelho, que, ao contrário da professora Clara, favorecia sempre os mais novos. A disciplina de matemática era ministrada pelo professor Astor Lima que era "bravo" ou pelo menos buscava manter uma postura mais rígida diante dos alunos, porém "ninguém se importava com a braveza dele", segundo pala-

5 Atualmente o Colégio está localizado na Avenida Tiradentes, no centro da cidade. 
vras do entrevistado. Na grade curricular havia ainda o latim que era ministrado por um padre francês, o qual o entrevistado não identificou, também aulas de canto e francês, disciplinas ministradas pelas madres Maria Marcel e Terezinha, respectivamente.

\begin{abstract}
Olha, eu não gostava do inglês, por exemplo, não gostava justamente por causa das ligações da professora Clara com os mais velhos e os mais novos não tinham vez não; e geografia, por exemplo, que era Poti Coelho, ele era enérgico com os novos, com os pequenos, mas com os outros (...). Nós tínhamos um professor de matemática ele (...). Eu gostava de matemática, eu sempre gostei de matemática; naquela época, tinha latim e francês, tudo no ginásio, né. Nosso professor de latim era um padre e o de francês era madre Maria Marcel, e a professora de canto era uma irmã, a madre Terezinha, era muito boa; Maria Marcel era brava (COSTA, 2005).
\end{abstract}

Os relatos acima apontam para uma série de elementos que compõem o cotidiano escolar, como as normas, as disciplinas, bem como a nomeação de sujeitos, a descrição de amizades, as travessuras, os medos, os sonhos realizados ou não, as frustrações, as decepções, as mágoas, entre tantos outros sentimentos que muitas vezes não podem ser descritos com palavras, mas são perceptíveis em olhares, gestos, tons de fala... Essas narrativas possibilitaram compreender um pouco desse universo tão relevante na vida dos sujeitos que o frequenta. De maneira que nos permite perceber um pouco da escola a partir dos olhares dos(as) alunos(as), que carregam sentidos e significados diferentes, dos pais, dos professores, dos diretores e daqueles que estão de fora desse contexto/ambiente.

\title{
Considerações finais
}

Após os parágrafos acima, pode-se concluir que os estudos da memória são, assim como os documentos escritos, fontes essenciais para se conhecer a história das instituições escolares, bem como o currículo, o cotidiano e a infinitas possibilidades que essa fonte traz em si mesma, como os fatos e os acontecimentos, as práticas culturais etc. que colocam em evidência as "memórias de experiências" e os sentidos de seus usos 
por um determinado grupo social. Desse modo, reconstruir e ativar o passado, mediante a memória coletiva e as experiências que se encontram escritas ou inscritas nas mais diversas relações tecidas pelos sujeitos no ambiente escolar, possibilitaram também repensar o sentido da escola e das interações dos atores sociais nesse ambiente, significa entre outras coisas instigá-la a revisitar as experiências registradas ou contadas.

Mediante o conjunto de narrativas orais aqui trabalhado, foi possível explorar um pouco da escola a partir dos olhares de alguns alunos, estes, por sua vez, mediante suas narrativas reconstruíram e ressignificaram um passado distante. As descrições sobre a escola e o cotidiano escolar permitiram compreender um pouco sobre a conjuntura da educação em Cáceres nas primeiras décadas do século XX, revelaram várias facetas que compõem o cotidiano escolar, como as travessuras, as redes de amizades e as sociabilidades, as normas, os(as) professores(as), enfim, um conjunto de elementos que possibilitam "desenhar" e consequentemente conhecer mais sobre a educação na cidade. As memórias dos sujeitos que falaram eternizam a escola, ao mesmo tempo em que permitem compreender as dinâmicas que nela se estabelecem, possibilitando entendê-la para além da sua função de alfabetizar, de disciplinar e/ou de moldar os indivíduos.

\section{Referências}

ARÓSTEGUI, Julio. La historia vivida: sobre la historia del presente. Madri: Alianza Editorial, 2004.

CARMO, Roney Gusmão do. Memória social do aluno-trabalhador sobre a escola noturna. 2011. 135 f. Dissertação (Mestrado em Memória: Linguagem e Sociedade). Universidade Estadual do Sudoeste da Bahia, Vitória da Conquista, 2011.

CUSTÓDIO, Regiane Cristina. Memórias da migração, memórias da profissão: narrativas de professoras sobre suas vivências nas décadas de 1960 a 1980 (Tangará da Serra- MT). 2014. 211 f. Tese (Doutorado em Educação). Faculdade de Educação, Universidade Federal do Rio Grande do Sul, 2014. 
NUNES, Clarice. Memória e História da Educação: entre práticas e representações. In: Maria Cristina Leal; Marília Pimentel (Orgs.). História e Memória da Escola Nova. V. 1. Rio de Janeiro: Loyola, 2003. p. 9-26.

SÁ, Elizabeth Figueiredo de. De criança a aluno: as representações da escolarização da infância em Mato Grosso (1910-1927). Cuiabá, EdUFMT, 2007.

SILVA, Adriane Cristine. Grupo Escolar Esperidião Marques: uma contribuição para os estudos das Instituições Escolares em Mato Grosso 1910 - 1947. 2011. 185 f. Dissertação (Mestrado em Educação) - Faculdade de Educação, Universidade Federal da Grande Dourados, Dourados, 2011.

TEIXEIRA, Maria Lúcia Aguiar. A escola como lugar de memória. In: XXVIII ENCONTRO NACIONAL DE HISTÓRIA. Lugares dos historiadores: velhos e novos desafios, 2015. Florianópolis/SC. Anais Eletrônicos. 2015. p. 1-9. Disponível em: http://www.snh2015.anpuh.org Acesso em: 17 set. 2015 .

XAVIER, Ana Paula da Silva. Processos educativos da infância em Cuiabá (1870-189o). 2012. 195 fls. Tese (Doutorado em Educação). Faculdade de Educação. Universidade Federal de Minas Gerais, Belo Horizonte, 2012.

\section{Fontes orais}

ARRUDA, Clarice. (61 anos). (jun. 2005). Entrevistadora: Maria do Socorro, Cáceres/MT, 06 de junho de 2005.

COSTA, Gregório. (70 anos). (abr. 2005). Entrevistadora: Maria do Socorro, Cáceres/MT, 27 de abril de 2005.

MORAIS, Lúcio. (94 anos). (abr. 2005). Entrevistadora: Maria do Socorro, Cáceres/MT, 20 de abril de 2005.

MOREIRA, Paulo. (61 anos). (fev. 2006). Entrevistadora: Maria do Socorro, Cáceres/MT, 19 de fevereiro de 2006.

Recebido em 17 de março de 2016. Aprovado em 17 de junho de 2016. 